\title{
Kinerja Karyawan: Peran Kualitas Sumber Daya Manusia, Lingkungan Kerja, dan Budaya Organisasi
}

\author{
Maria Rosvita Hoar, Ignatius Soni Kurniawan, Jajuk Herawati \\ Fakultas Ekonomi, Universitas Sarjanawiyata Tamansiswa, Yogyakarta \\ *Correspondence email: soni_kurniawan@ustjogja.ac.id
}

\begin{abstract}
This study aims to examine the effect of the quality of human resources, work environment, and organizational culture on employee performance. The sampling technique used a saturated sample, with as many as 50 employees at Kantor Pusat Waroeng Spesial Sambal Yogyakarta. Primary data was taken by using a questionnaire. Data were analyzed using multiple linear regression analysis. The results showed that the quality of human resources, work environment, and organizational culture had a positive and significant effect on employee performance. The implication directs the leadership to maintain or improve the implementation of the antecedent variables of employee performance.
\end{abstract}

Keywords: organizational culture; employee performance; quality of human resources; work environment,

\section{Pendahuluan}

Persaingan bisnis yang ketat mendorong sumber daya manusia (SDM) untuk semakin berkualitas dengan mengarahkan pada upaya untuk bertahan hidup. Sumber daya manusia merupakan aset penting untuk membangun keunggulan perusahaan dibanding aset lain. Namun demikian SDM juga perlu didukung dengan kondisi lingkungan kerja dan budaya yang mendukung untuk berkinerja dalam organisasi. Kondisi yang nyaman dan budaya organisasi yang mendukung penciptaan etos kerja profesional akan mengarahkan masing-masing anggota organisasi untuk berkinerja dengan baik yang pada akhirnya membantu pencapaian tujuan perusahaan. Upaya meningkatkan kualitas SDM yang harus dilakukan perusahaan adalah dengan melakukan peningkatan kapasitas individu dan kerjasama kelompok. Karyawan dibangun untuk menjadi aset yang mampu mengaktifkan aset lainnya untuk mencapai kinerja individu yang lebih baik. Menurut Winedar, Wibowo, \& Muninghar (2019) kualitas SDM mempunyai pengaruh positif dan signifikan terhadap kinerja karyawan, yaitu apabila SDM pada perusahaan memenuhi tanggung jawab atas pekerjaannya maka karyawan dapat menghasilkan kinerja sesuai standar atau kriteria yang telah ditetapkan organisasi. Begitu pula sebaliknya jika kualitas SDM kurang baik, maka kinerja karyawan juga semakin rendah.

Sibagariang (2013) menyatakan bahwa kualitas SDM tidak berpengaruh signifikan terhadap kinerja karyawan, hal ini artinya bahwa agar SDM berkinerja dengan baik dibutuhkan faktor lain yang antara lain adalah lingkungan kerja yang layak. Lingkungan kerja terdiri atas dua hal yaitu lingkungan kerja fisik dan lingkungan kerja nonfisik. Lingkungan kerja yang aman dan sesuai kebutuhan akan mencegah karyawan dari cidera, mengurangi kejenuhan dan kelelahan sehingga memperlama daya tahan karyawan untuk bekerja. Lingkungan kerja yang kotor, berantakan, dan tidak sehat akan menyebabkan rasa tidak nyaman bagi karyawan yang membuatnya sulit untuk bertahan di ruangan tersebut apalagi untuk berkinerja. Prakoso (2014) menyatakan lingkungan kerja berpengaruh signifikan terhadap kinerja karyawan, sehingga diharapkan perusahaan mengupayakan sarana dan prasarana yang memadai di tempat kerja. Pimpinan juga diharapkan mampu membangun hubungan yang harmonis antar sesama karyawan, agar karyawan merasa betah dan terpenuhi kebutuhan sosialnya sebagai bentuk lingkungan kerja nonfisik.

Penelitian Logahan, Tjoe, \& Naga (2012) menyatakan sebaliknya, menurut mereka lingkungan kerja tidak berpengaruh signifikan terhadap kinerja karyawan. Temuan tidak ada pengaruh lingkungan membuktikan bahwa ada variabel lain selain lingkungan yang menentukan kinerja. Penelitian Koesmono (2005) serta Amanda, Budiwibowo, \& Amah, 2017) menunjukkan adanya pengaruh yang positif dan signifikan budaya organisasi terhadap kinerja karyawan, budaya organisasi merupakan salah satu identitas perusahaan yang didalamnya terdapat nilai-nilai dan aturan yang disepakati dan dilaksanakan dalam organisasi. Budaya yang kuat dan mendukung standar etika yang tinggi, akan memberi pengaruh positif terhadap peningkatan kinerja karyawan, karyawan dapat bekerja dengan baik apabila ada dorongan dari dalam diri sendiri maupun dorongan dari perusahaan. Meskipun demikian tidak semua penelitian mengkonfirmasi bahwa budaya organisasi berpengaruh positif terhadap kinerja. Penelitian Nurdinah \& Kurniawan (2019) menunjukan budaya organisasi tidak berpengaruh secara singnifikan terhadap kinerja, sedangkan Parimita, Prayuda, \& Wahyu (2013) menyatakan secara empiris budaya organisasi memiliki pengaruh negatif yang signifikan terhadap kerja karyawan. Meskipun terjadi inkonsistensi hasil penelitian terdahulu, riset ini mencoba menggabungkan kombinasi kualitas SDM, lingkungan dimana dia bekerja, dan budaya organisasi sebagai anteseden dari kinerja. Riset ini bertujuan untuk memahami apa penyebab kinerja karyawan di Kantor Pusat Waroeng Spesial Sambal yang mengelola banyak cabang di Indonesia melalui anteseden kualitas SDM, lingkungan kerja, dan budaya organisasi. 


\section{Tinjauan Literatur}

\section{Kualitas Sumber Daya Manusia}

Sumber daya manusia adalah potensi aset dan berfungsi sebagai modal nonmaterial atau nonfinansial pada organisasi bisnis, yang dapat diwujudkan menjadi potensi nyata secara fisik dan nonfisik untuk menguatkan eksistensi organisasi (Nawawi, 2003). Kualitas SDM dapat dilihat pada kemampuan karyawan ketika melaksanakan tugas dan tanggung jawab yang diberikan kepadanya dengan bekal pendidikan, pelatihan, dan pengalaman yang cukup memadai. Kualitas merupakan suatu ukuran yang menyatakan seberapa jauh telah dipenuhi berbagai persyaratan, spesifikasi, dan harapan; SDM adalah tenaga kerja atau karyawan di dalam suatu organisasi yang mempunyai peran penting dalam mencapai keberhasilan (Sedarmayanti, 2017). Lebih lanjut Werther \& Davis (1996), menyatakan bahwa SDM adalah pegawai yang siap, mampu dan siaga dalam mencapai tujuan-tujuan organisasi; dimensi pokok sisi sumber daya adalah kontribusinya terhadap organisasi, sedangkan dimensi pokok manusia adalah perlakuan kontribusi terhadapnya yang pada gilirannya akan menentukan kualitas dan kapabilitas hidupnya. Meskipun organisasi didukung dengan sarana dan prasarana serta dana yang berkecukupan namun tujuan perusahaan sulit terpenuhi bila tanpa dukungan SDM yang andal. SDM merupakan kunci pokok, makna kunci pokok adalah SDM merupakan faktor penentu keberhasilan kegiatan perusahaan.

\section{Lingkungan Kerja}

Sedarmayanti, (2007) menyatakan bahwa lingkungan kerja fisik adalah semua keadaan berbentuk fisik yang terdapat di sekitar tempat kerja yang dapat mempengaruhi karyawan baik secara langsung maupun secara tidak langsung; sedangkan lingkungan kerja nonfisik adalah keadaan yang terjadi berkaitan dengan hubungan kerja, baik hubungan dengan atasan maupun dengan rekan kerja, ataupun hubungan dengan bawahan. Ahyari (1999) menegaskan bahwa lingkungan kerja merupakan lingkungan tempat para pekerja melaksanakan tugas dan pekerjaannya. Menurut George \& Rue (2010) lingkungan kerja dapat diartikan sebagai kekuatan-kekuatan yang mempengaruhi, baik secara langsung maupun tidak langsung terhadap kinerja organisasi. Lingkungan kerja adalah sesuatu yang ada di sekitar para pekerja yang dapat mempengaruhi dirinya dalam melaksanakan pekerjaan yang antara lain berupa temperatur, kelembapan, ventilasi udara, penerangan, keheningan, kebersihan, dan memadai atau tidaknya perlengkapan kerja (Isyandi, 2004). Pihak manajemen perusahaan hendaknya membangun suatu iklim dan suasana kerja yang bisa membangkitkan rasa kekeluargaan untuk mencapai tujuan bersama; perusahaan hendaknya mampu mendorong inisiatif dan kreativitas, kondisi inilah yang menciptakan antusiasme untuk bersatu ketika mencapai tujuan organisasi (Sentoso, 2011).

\section{Budaya Organisasi}

Menurut Robbins \& Judge (2013) budaya organisasi merupakan sistem makna bersama yang dianut oleh anggotanya yang membedakannya dari organisasi lain, sistem makna bersama ini bila diamati dengan lebih seksama, merupakan seperangkat karakteristik utama yang dihargai bersama oleh suatu organisasi. Budaya organisasi terkait dengan pola kebiasaan dan hal-hal yang dihargai dan dijunjung dalam perusahaan. Budaya organisasi adalah pola tingkah laku yang dikembangkan oleh suatu organisasi yang dipelajarinya ketika menghadapi masalah adaptasi eksternal dan integrasi internal, yang telah terbukti berhasil sehingga disahkan dan diajarkan kepada anggota baru sebagai cara untuk menyadari, berpikir, serta merasakan (David, 2004). Lebih lanjut budaya organisasi juga adalah seperangkat sistem nilai-nilai (values), keyakinan-keyakinan, asumsi-asumsi atau norma-norma yang telah lama berlaku, disepakati dan diikuti oleh para anggota suatu organisasi sebagai pedoman perilaku dan pemecahan masalahmasalah organisasi (Darodjat, 2015). Semakin meningkatnya bukti bahwa hanya perusahaan-perusahaan dengan budaya organisasi yang efektif yang dapat menciptakan peningkatan produktivitas, meningkatkan rasa ikut memiliki dari karyawan, dan pada akhirnya meningkatkan keuntungan perusahaan (Moeljono, 2003).

\section{Kinerja Karyawan}

Hasil kerja secara kualitas dan kuantitas yang dicapai oleh individu terkait pelaksanaan tugas sesuai dengan tanggung jawab yang diberikan organisasi kepadanya disebut kinerja (Mangkunegara, 2011). Kinerja merupakan gambaran mengenai tingkat pencapaian pelaksanaan suatu program kebijakan sebagai bagian organisasi dalam mewujudkan visi dan misi melalui perencanaan strategisnya (Moeheriono, 2009). Kinerja dapat dilihat dari dua hal, pertama adalah sebagai hasil atau output yaitu menilai apa yang telah dicapai oleh seseorang, kedua adalah aspek prosesnya untuk mencapai hasil (Pfeffer, 2013). Hasil dan proses tersebut merupakan perilaku nyata yang ditampilkan setiap orang yang dihasilkan sesuai dengan perannya dalam perusahaan Rivai (2010). Mathis \& Jackson (2006) menegaskan bahwa kinerja mengukur apa yang dilakukan atau tidak dilakukan karyawan; kinerja karyawan mempengaruhi seberapa banyak mereka memberi kontribusi kepada organisasi meliputi kuantitas dan kualitas output, jangka waktu output, kehadiran di tempat kerja, dan sikap kooperatif. 


\section{Pengembangan Hipotesis}

Kualitas SDM mengarah pada kemampuan individu terkait tugas dan tanggung jawab yang dikaitkan dengan kompetensi dan latar belakang pendidikan dan keterampilan. Leuhery, (2018) serta Gerhana, Rezti, \& Wasis (2019), menyatakan bahwa kualitas SDM berpengaruh positif dan signifikan terhadap kinerja karyawan. Sumber daya manusia memiliki peranan yang besar dalam suatu organisasi. Kualitas SDM yang tinggi akan terlihat dari besarnya kontribusi dalam memenangkan kompetisi antar organisasi. SDM kompeten adalah karyawan atau anggota organisasi yang memenuhi karakteristik yaitu memiliki pengetahuan dan keterampilan cukup untuk mampu melaksanakan tugastugas yang diberikan serta kemampuan bekerja sama dengan orang lain. Karendra (2014) menegaskan pentingnya kontribusi SDM yang kompeten pada kinerja. Perusahaan dapat bertahan jika memiliki kompetensi manajerial yang memenuhi atau diatas standar dikaitkan dengan pencapaian visi dan misi perusahaan.

$\mathrm{H}_{1}$ : Kualitas SDM berpengaruh positif terhadap kinerja karyawan.

Nitisemito (1996) menyatakan bahwa lingkungan kerja adalah segala sesuatu yang ada di sekitar para pekerja dan yang dapat mempengaruhi dirinya dalam menjalankan tugas yang dibebankan; lingkungan kerja terdiri dari lingkungan fisik dan nonfisik yang melekat pada karyawan sehingga tidak dapat dipisahkan perannya dalam mendukung kinerja. Hasil penelitian sebelumnya yang dilakukan oleh Pratiwi, Nuryanti, \& Daulay (2014) serta Lestary \& Harmon (2018) menyatakan bahwa lingkungan kerja berpengaruh positif dan signifikan terhadap kinerja karyawa. Lingkungan kerja yang kondusif memberikan rasa aman dan memungkinkan karyawan untuk dapat bekerja optimal. Jika karyawan menyukai lingkungan kerja dimana dia bekerja, maka karyawan akan melakukan aktivitasnya dengan baik sehingga waktu kerja dipergunakan secara efektif.

$\mathrm{H}_{2}$ : Lingkungan kerja berpengaruh positif terhadap kinerja karyawan.

Priansa \& Garnida (2012) menyatakan bahwa budaya organisasi merupakan sistem nilai yang dikembangkan dan berlaku dalam suatu organisasi, yang menjadik ciri khas sebuah organisasi. Budaya organisasi merupakan nilai, anggapan, asumsi, sikap, dan norma perilaku yang melembaga kemudian diwujudkan dalam penampilan, sikap, dan tindakan sehingga menjadi identitas dari organisasi tertentu (Sudarmanto, 2009). Hasil penelitian oleh Amanda et al. (2017), Winedar et al. (2019) dan Pratiwi et al. (2014) menunjukan bahwa budaya organisasi berpengaruh positif dan signifikan terhadap kinerja karyawan. Keberhasilan suatu organisasi atau lembaga dalam mencapai tujuannya tidak terlepas dari SDM yang dimiliki, karena SDM yang mengelola sumber daya lain yang dimiliki organisasi untuk membantu mewujudkan tujuan organisasi. Terdapat nilai-nilai dan aturan yang disepakati dan dilaksanakan dalam budaya organisasi. Jika budaya organisasi yang tercipta baik dan positif, maka akan memberikan dampak pada peningkatan kinerja karyawan.

$\mathrm{H}_{3}$ : Budaya organisasi berpengaruh positif terhadap kinerja karyawan.

\section{Metode}

Penelitian ini dilakukan pada Kantor Pusat Waroeng Spesial Sambal atau lebih dikenal dengan Waroeng SS yang bergerak pada bisnis kuliner dengan lokasi di Jl. Kaliurang Km. 4.5 Yogyakarta. Populasi dalam penelitian ini adalah karyawan Kantor Pusat Waroeng Spesial Sambal Yogyakarta. Sampel yang digunakan dalam penelitian ini sebanyak 50 karyawan. Adapun ukuran sampel dalam penelitian ini adalah sebanyak 50 responden yang diambil dengan menggunakan teknik pengambilan sampel jenuh. Pengumpulan data dalam penelitian ini menggunakan daftar pertanyaan berupa kuesioner yang dibagikan langsung kepada karyawan. Pengukuran kualitas SDM meliputi pengetahuan, keterampilan, dan kemampuan (Matutina, 2001); lingkungan kerja meliputi penerangan/cahaya, sirkulasi udara, kebisingan, bau tidak sedap, dan keamanan (Sedarmayanti, 2007); budaya organisasi meliputi inovasi dan pengambilan resiko, perhatian ke hal yang rinci dan detil, orientasi hasil, orientasi orang, orientasi tim, keagresifan, serta kemantapan/stabilitas (Robbins \& Coulter, 2010); kinerja karyawan meliputi kualitas, kuantitas, pelaksanaan tugas, dan tanggung jawab (Mangkunegara, 2011). Setiap pilihan jawaban responden diberi skor nilai atau bobot yang disusun secara bertingkat berdasarkan skala Likert Sangat Setuju (5), Setuju (4), Netral (3), Tidak Setuju (2) Sangat Tidak Setuju (1).

\section{Hasil}

Tabel 1

Karakteristik Responden

\begin{tabular}{|l|r|r|}
\hline \multicolumn{1}{|c|}{ Kategori } & Frekuensi & \multicolumn{1}{c|}{ Persen } \\
\hline Jenis Kelamin & & \\
Laki-laki & $32 \%$ \\
Perempuan & 34 & \\
Usia & & $37 \%$ \\
$<30$ Tahun & $74 \%$
\end{tabular}


Maria Rosvita Hoar et al., Kinerja Karyawan: Peran Kualitas Sumber Daya Manusia, Lingkungan Kerja, dan Budaya Organisasi

\begin{tabular}{|c|c|c|}
\hline \multirow{2}{*}{\multicolumn{3}{|c|}{$\begin{array}{l}\text { 31-39 Tahun } \\
\text { Pendidikan Terakhir }\end{array}$}} \\
\hline & & \\
\hline SMA/sederajat & 5 & $10 \%$ \\
\hline Diploma & 11 & $22 \%$ \\
\hline S-1 & 33 & $66 \%$ \\
\hline S-2 & 1 & $2 \%$ \\
\hline \multicolumn{3}{|l|}{ Masa Bekerja } \\
\hline$<2$ Tahun & 19 & $38 \%$ \\
\hline 2-5 Tahun & 10 & $20 \%$ \\
\hline 6-10 Tahun & 19 & $38 \%$ \\
\hline 11-15 Tahun & 2 & $4 \%$ \\
\hline \multicolumn{3}{|l|}{ Status Kepegawaian } \\
\hline Tetap & 6 & $12 \%$ \\
\hline Tidak Tetap & 44 & $88 \%$ \\
\hline \multicolumn{3}{|l|}{ Status Pernikahan } \\
\hline Menikah & 21 & $42 \%$ \\
\hline Belum menikah & 28 & $56 \%$ \\
\hline Janda/Duda & 1 & $2 \%$ \\
\hline
\end{tabular}

Sumber: data olahan

Tabel 1 menyajikan karakteristik responden dengan sebagian besar responden adalah perempuan (68\%). Berdasarkan usia, mayoritas responden $<30$ tahun (74\%), sedangkan menurut tingkat pendidikan terakhir mayoritas responden adalah lulusan S-1 (66\%). Berdasar lama bekerja responden, mayoritas < 2 tahun (38\%) dan 6-10 tahun, (38\%). Responden didominasi pegawai tidak tetap (88\%), dan 56\% karyawan belum menikah. Pengujian validitas pada Tabel 2 menghasilkan $\mathrm{r}$ hitung kualitas sumber daya manusia (0.758 s.d 0.813), lingkungan kerja (0.557 s.d 0.792), budaya organisasi (0.602 s.d 0.837), kinerja karyawan (0.663 s.d 0.845). Nilai $\mathrm{r}$ hitung $>\mathrm{r}$ tabel 5\% (0.2353) yang artinya semua item adalah valid. Cronbach's Alpha kualitas SDM (0.798), lingkungan kerja (0.892), budaya organisasi (0.859) dan kinerja karyawan $(0.885)>0.6$ atau instrumen reliabel. Tabel 3 hasil uji asumsi klasik menunjukan tidak terjadi heteroskedastisitas (Glejser test >0.05), dan normalitas (Kolmogorov-Smirnov Z, Asymp, Sig. >0.05). Multikolonieritas tidak terjadi pada model regresi dengan tolerance $>0.10$ dan $V I F<10$.

Hasil uji regresi liner berganda disajikan pada Tabel 4. Hasil uji t menunjukkan pengaruh semua variabel bebas terhadap variabel terikat memiliki nilai signifikansi $<0.05$. Dengan demikian diperoleh penerimaan $\mathrm{H}_{1}$ (kualitas SDM berpengaruh positif pada kinerja karyawan), $\mathrm{H}_{2}$ (lingkungan kerja berpengaruh positif terhadap kinerja karyawan), dan $\mathrm{H}_{3}$ (budaya organisasi berpengaruh positif terhadap kinerja karyawan). Nilai koefisien determinasi menunjukkan bahwa $80.8 \%$ kinerja karyawan dipengaruhi oleh kualitas SDM, lingkungan kerja, dan budaya kerja, sedangkan $19.2 \%$ dipengaruhi oleh variabel yang tidak diteliti. Nilai koefisien determinasi tersebut tinggi karena sudah $80 \%$.

Tabel 2

Uji Validatas dan Reliabilitas

\begin{tabular}{|c|c|c|c|c|c|c|c|}
\hline KSDM & Corr. Item & LK & Corr. Item & $\mathrm{BO}$ & Corr. Item & KK & Corr. Item \\
\hline KSDM1 & 0.813 & LK1 & 0.609 & BO1 & 0.782 & KK1 & 0.760 \\
\hline KSDM2 & 0.758 & LK2 & 0.715 & $\mathrm{BO} 2$ & 0.695 & $\mathrm{KK} 2$ & 0.845 \\
\hline KSDM3 & 0.788 & LK3 & 0.680 & $\mathrm{BO} 3$ & 0.761 & KK3 & 0.809 \\
\hline KSDM4 & 0.804 & LK4 & 0.776 & $\mathrm{BO} 4$ & 0.704 & KK4 & 0.686 \\
\hline & & LK5 & 0.792 & BO5 & 0.837 & KK5 & 0.663 \\
\hline & & LK6 & 0.769 & BO6 & 0.602 & KK6 & 0.788 \\
\hline & & LK7 & 0.717 & $\mathrm{BO} 7$ & 0.785 & KK7 & 0.845 \\
\hline & & LK8 & 0.661 & & & & \\
\hline & & LK9 & 0.656 & & & & \\
\hline & & LK10 & 0.716 & & & & \\
\hline & & LK11 & 0.557 & & & & \\
\hline Cronbach's Alpha & 0.798 & & 0.892 & & 0.859 & & 0.885 \\
\hline
\end{tabular}

Ket. KSDM: Kualitas Sumber Daya Manusia; LK: Lingkungan Kerja; BO: Budaya Organisasi; KK: Kinerja Karyawan.

Sumber: data olahan 
Maria Rosvita Hoar et al., Kinerja Karyawan: Peran Kualitas Sumber Daya Manusia, Lingkungan Kerja, dan Budaya Organisasi

Tabel 3

Hasil Asumsi Klasik

\begin{tabular}{|c|c|c|c|c|c|}
\hline \multicolumn{2}{|c|}{ Variabel } & \multirow{2}{*}{$\frac{\text { Heteroskedastisitas }}{\text { Sig. }}$} & \multirow{2}{*}{$\begin{array}{l}\text { Normalitas. } \\
\text { Asymp. Sig. }\end{array}$} & \multicolumn{2}{|c|}{ Multikolonieritas } \\
\hline Ind & Dep. & & & Tol. & $V I F$ \\
\hline KSDM & & 0.250 & & 0.575 & 1.740 \\
\hline LK & KK & 0.909 & 0.797 & 0.246 & 4.059 \\
\hline BO & & 0.305 & & 0.266 & 3.756 \\
\hline
\end{tabular}

Ket. KSDM: Kualitas Sumber Daya Manusia; LK: Lingkungan Kerja; BO: Budaya Organisasi; KK: Kinerja Karyawan.

Sumber: data olahan

Tabel 4

Hasil Regresi Berganda

\begin{tabular}{|l|c|r|r|r|r|r|}
\hline \multirow{2}{*}{ Model } & \multicolumn{2}{|c|}{ Unstandardized Coefficients } & Standardized Coefficients & \multirow{2}{*}{$t$} & \multirow{2}{*}{ Sig. } & \multirow{2}{*}{ Adj. $R^{2}$} \\
\cline { 2 - 8 } & B & Std. Error & Beta & & & \\
\hline (Constant) & 1.250 & 1.937 & & 0.645 & 0.522 & \\
Kualitas SDM & 0.379 & 0.146 & 0.429 & 2.605 & 0.012 & \\
Lingkungan Kerja & 0.253 & 0.076 & 0.800 & 0.001 & 0.808 \\
Budaya Organisasi & 0.360 & 0.125 & 0.350 & 2.882 & 0.006 & \\
\hline
\end{tabular}

Sumber: data olahan

Pengujian hipotesis 1 menghasilkan bahwa kualitas SDM berpengaruh positif terhadap kinerja karyawan. Pada dasarnya sumber daya sangat berperan aktif terhadap proses berjalannya pekerjaan didalam organisasi maupun untuk pencapaian tujuan perusahaan. Peralatan canggih yang dimiliki perusahaan akan kurang manfaatnya jika karyawan tidak mampu menggunakannya dengan maksimal. Salah satu upaya dalam meningkatkan kualitas SDM adalah pengembangan keterampilan. Keterampilan karyawan merupakan kemampuan dan penguasaan teknis operasional di bidang tertentu yang dimiliki karyawan. SDM yang memiliki keterampilan hasil kerjanya akan lebih baik dibanding yang tidak terampil. Dengan demikian sangat penting bagi perusahaan untuk mampu menciptakan karyawan yang berkualitas, karena semakin baik kualitas SDM maka semakin meningkat kinerjanya. Hasil penelitian ini sejalan dengan penelitian sebelumnya yang dilakukan Telaumbanua (2019) yang menyatakan bahwa kualitas SDM berpengaruh positif dan signifikan terhadap kinerja karyawan.

Pengujian hipotesis 2 menunjukkan bahwa lingkungan kerja merupakan hal yang mempengaruhi kinerja individu. Lingkungan fisik maupun nonfisik yang kondusif akan memberikan rasa nyaman kepada karyawan untuk bekerja. Sebaliknya jika lingkungan kerja tersebut kurang baik maka karyawan akan terganggu konsentrasinya dan kondisi fisiknya turun sehingga tidak mampu mempertahankan konsistensi kerja baiknya. Hubungan baik antara atasan dan karyawan maupun sesama karyawan akan meningkatkan semangat kerja karyawan. Hasil penelitian ini sejalan dengan penelitian sebelumnya yang dilakukan oleh Rosa (2015) dan Prakoso (2014) yang menyatakan bahwa lingkungan kerja berpengaruh positif dan signifikan terhadap kinerja karyawan. Hasil uji hipotesis tiga menyatakan bahwa kinerja individu dipengaruhi oleh budaya organisasi. Budaya yang dianut bersama dalam organisasi akan membentuk pola perilaku anggota organisasi sesuai dengan nilai-nilai yang berlaku pada perusahaan. Oktaviani \& Rahardjo (2014) menjelaskan bahwa budaya organisasi yang kuat akan mempengaruhi pola pikir dan tindakan karyawan dalam menyelesaikan tugas-tugasnya. Perusahaan yang memiliki budaya yang kuat akan mampu meningkatkan kinerja karyawannya, menumbuhkan semangat kebersamaan dikalangan para anggotanya, meningkatkan rasa nyaman dan loyal terhadap perusahaan serta mampu membesarkan keuntungan perusahaan. Hasil penelitian ini sesuai dengan penelitian terdahulu yang dilakukan oleh Himma (2020) serta Sagita, Susilo, \& Cahyo (2018) yang menyatakan bahwa budaya organisasi berpengaruh positif dan signifikan terhadap kinerja karyawan.

\section{Simpulan}

Hasil penelitian menyatakan kualitas SDM, lingkungan kerja, dan budaya organisasi berpengaruh positif terhadap kinerja karyawan Kantor Pusat Waroeng Spesial Sambal Yogyakarta. Sebagai implikasinya maka pimpinan diharapkan mempertahankan atau meningkatkan dimensi implementasi dari kualitas SDM, kondisi lingkungan kerja, dan budaya organisasi bila ingin meningkatkan kinerja karyawannya. Penelitian ke depan dapat mempertimbangkan untuk melibatkan variabel lain yang dapat mempengaruhi kinerja, misalnya motivasi kerja (Ulfah, Subiyanto, \& Kurniawan, 2020), motivasi kerja intrinsik dan ekstrinsik mampu menggerakkan individu untuk merubah kondisi kinerja yang biasa menjadi lebih tinggi. 
Maria Rosvita Hoar et al., Kinerja Karyawan: Peran Kualitas Sumber Daya Manusia, Lingkungan Kerja, dan Budaya Organisasi

\section{Daftar Pustaka}

Ahyari, A. (1999). Manajemen Produksi Perencanaan Sistem Produksi (4th ed.). Yogyakarta: BPFE.

Amanda, E. A., Budiwibowo, S., \& Amah, N. (2017). Pengaruh Budaya Organisasi Terhadap Kinerja Karyawan di PDAM Tirta Taman Sari Kota Madiun. Assets: Jurnal Akuntansi Dan Pendidikan, 6(1), 1-12. https://doi.org/10.25273/jap.v6i1.1289

Darodjat, A. T. (2015). Konsep-Konsep Dasar Manajemen Personalia. Bandung: PT Refika Aditama.

David, F. R. (2004). Manajemen Strategi, Konsep. Jakarta: Prehalindo.

George, R. T., \& Rue, L. W. (2010). Dasar-Dasar Manajemen. Jakarta: Bumi Aksara.

Gerhana, W., Rezti, R., \& Wasis, W. (2019). Pengaruh Kualitas Sumber Daya Manusia dan Profesionalisme terhadap Kinerja Karyawan dengan Komitmen Organisasi sebagai Variabel Intervening (Studi Kasus pada Karyawan Dinas Pendidikan Hulu Sungai Selatan). Jurnal Riset Inspirasi Manajemen Dan Kewirausahaan, 3(1), 49-57. https://doi.org/10.35130/jrimk.v3i1.50

Himma, M. (2020). Analisis Pengaruh Faktor Lingkungan Kerja Dan Budaya Organisasi Terhadap Kinerja Karyawan. Adbis: Jurnal Administrasi Dan Bisnis, 14(2), 130-139.

Isyandi. (2004). Manajemen Sumber Daya Manusia. Jakarta: Unri Pres.

Karendra, I. A. (2014). Pengaruh Kualitas Sumber Daya Manusia Terhadap Perkembangan Usaha Pada KPRI Pertaguma Kota Madiun. Equilibrium, 2(2), 189-198.

Koesmono, H. T. (2005). Pengaruh Budaya Organisasi Terhadap Motivasi Dan Kepuasan Kerja Serta Kinerja Karyawan Pada Sub Sektor Industri Pengolahan Kayu Skala Menengah Di Jawa Timur. Jurnal Manajemen \& Kewirausahaan, 7(2), 163-179. https://doi.org/10.1109/MS.2008.35

Lestary, L., \& Harmon, H. (2018). Pengaruh Lingkungan Kerja Terhadap Kinerja Karyawan. Jurnal Riset Bisnis Dan Investasi, 3(2), 94-103. https://doi.org/10.35697/jrbi.v3i2.937

Leuhery, F. (2018). Pengaruh Kualitas Sumber Daya Manusia, Disiplin Kerja, dan Pengembangan Karir Terhadap Prestasi Kerja Pegawai Dinas Perhubungan Provinsi Maluku. Jurnal Manajemen /SOSOQ, 6.1(2), 88-98.

Logahan, J. M., Tjoe, T. F., \& Naga, N. (2012). Analisis Pengaruh Lingkungan Kerja dan Pemberian Kompensasi terhadap Kinerja Karyawan CV Mum Indonesia. Binus Business Review, 3(1), 573-586.

Mangkunegara, A. P. (2011). Manajemen Sumber Daya Manusia. Bandung: PT Remaja Rosdakarya.

Mathis, R. L., \& Jackson, J. H. (2006). Manajemen Sumber Daya Manusia (D. Angelica, ed.). Jakarta: Salemba Empat.

Matutina. (2001). Manajemen Sumber daya Manusia (2nd ed.). Jakarta: Gramedia Widia Sarana.

Moeheriono. (2009). Pengukuran Kinerja Berbasis Kompetensi. Bogor: Ghalia Indonesia.

Moeljono, D. (2003). Budaya Korparat dan Keunggulan Korporasi. Jakarta: PT. Elex Media Komputindo.

Nawawi, H. H. (2003). Manajemen Sumber Daya Manusia Untuk Bisnis Yang Kompetitif. Yogyakarta: Gadjah Mada University Press.

Nitisemito, A. S. (1996). Manajemen Personalia (Manajemen Sumber Daya Manusia). Jakarta: Ghalia Indonesia.

Nurdinah, S., \& Kurniawan, I. S. (2019). Pengaruh Budaya Organisasi, Reformasi Birokrasi, Remunerasi, dan Employee Engagement Terhadap Kinerja Pegawai. Upajiwa Dewantara, 3(1), 10-20.

Oktaviani, H., \& Rahardjo, M. (2014). Pengaruh Lingkungan Kerja dan Budaya Organisasi Terhadap Kinerja Karyawan Pada Koperasi Sumber Rejeki Rembang Jawa Tengah. Diponegoro Journal of Management, 4(1), $1-14$.

Parimita, W., Prayuda, W. H., \& Wahyu, H. agung. (2013). Pengaruh Lingkungan Kerja Dan Budaya Organisasi Terhadap Kepuasan Kerja Karyawan Pada Bank Btn (Persero) Cabang Bekasi. Jurnal Riset Manajemen Sains Indonesia (JRMSI), 4(2), 257-275.

Pfeffer, J. (2013). Paradigma Baru Manajemen Sumber Daya Manusia. Jakarta: Amara Books.

Prakoso, R. (2014). Pengaruh Lingkungan Kerja Terhadap Motivasi Kerja dan Kinerja Karyawan (Studi Pada Karyawan PT. AXA Financial Indonesia Cabang Malang). Jurnal Administrasi Bisnis JAB, 14(2), 1-10.

Pratiwi, A., Nuryanti, \& Daulay, I. N. (2014). Pengaruh Lingkungan Kerja Dan Budaya Organisasi Terhadap Kinerja Karyawan PT. Bank Riau Kepri Capem Duri. Jom FEKON, 1(2), 1-15.

Priansa, D. J., \& Garnida, A. (2012). Manajemen Perkantoran. Bandung: CV Alfabeta.

Rivai, V. (2010). Manajemen Sumber Daya Manusia untuk Perusahaan dari Teori ke Praktik. Jakarta: PT. Raja Grafindo.

Robbins, S. P., \& Coulter, M. (2010). Manajemen (10th ed.). Jakarta: Erlangga.

Robbins, S. P., \& Judge, T. A. (2013). Organizational Behavior. New York: Pearson.

Rosa, H. (2015). Pengaruh Lingkungan Kerja dan Pelatihan Terhadap Kinerja Karyawan PTPN VI Unit Ophir Sariak. E-Jurnal Apresiasi Ekonomi, 3(2), 187-197.

Sagita, A. A., Susilo, H., \& Cahyo, M. (2018). Pengaruh budaya organisasi terhadap kinerja karyawan dengan motivasi kerja sebagai variabel mediator (Studi pada PT Astra Internasional, Tbk-Toyota (Auto 2000) Cabang 
Maria Rosvita Hoar et al., Kinerja Karyawan: Peran Kualitas Sumber Daya Manusia, Lingkungan Kerja, dan Budaya Organisasi

Sutoyo Malang). Jurnal Administrasi Bisnis (JAB), 57(1), 73-82.

Sedarmayanti. (2007). Sumber Daya Manusia dan Produktivitas Kerja. Bandung: Mandar Maju.

Sedarmayanti. (2017). Manajemen Sumber Daya Manusia: Reformasi Birokrasi dan Manajemen Pegawai Negeri Sipil. Bandung: Refika Aditama.

Sentoso, S. P. (2011). Model Manajemen Sumber Daya Manusia Indonesia, Asia, dan Timur Jauh. Jakarta: Bumi Aksara.

Sibagariang, A. (2013). Pengaruh Kualitas Sumber Daya Manusia, Komunikasi, Sarana Pendukung, dan Komitmen Organisasi Terhadap Kinerja SKPD (Studi Empiris Pada Pemerintah Kota Sibolga). Jurnal Akuntansi, 1(1), 124.

Sudarmanto. (2009). Kinerja dan Pengembangan Kompetensi SDM. Yogyakarta: Pustaka Pelajar.

Telaumbanua, A. (2019). Pengaruh Kualitas Sumber Daya Manusia Terhadap Kinerja Pegawai Pada Badan Penanggulangan Bencana Daerah Kabupaten Nias Utara. Jurnal Akuntansi Dan Manajemen PEMBNAS, 5(1), $1-10$.

Ulfah, R. A., Subiyanto, D., \& Kurniawan, I. S. (2020). Peran Mediasi Motivasi Kerja Pada Pengaruh Gaya Kepemimpinan Transaksional Dan Kompensasi Terhadap Kinerja Karyawan. Jurnal Fokus, 10(2), 219-237.

Werther, W. B., \& Davis, K. (1996). Human Resources and Personal Management. New York: McGraw-Hill.

Winedar, S., Wibowo, N. M., \& Muninghar. (2019). Pengaruh Kualitas Sumber Daya Manusia, Budaya Organisasi Dan Profesionalisme Terhadap Kinerja Karyawan Bank PeWinedar, S., Wibowo, N. M., \& Muninghar. (2019). Pengaruh Kualitas Sumber Daya Manusia, Budaya Organisasi Dan Profesionalisme Terhadap Kinerja Ka. Jurnal Manajemen Dan Administrasi Publik, 53(9), 358-371. 